\title{
A review of secondary interfacility trauma transfers meeting provincial prehospital trauma triage guidelines
}

\author{
Taylor Bischoff ${ }^{1}$ Jonathan Briton ${ }^{2} \cdot$ Brad Baumber $^{2} \cdot$ Michael Lewell $^{2,3,4} \cdot$ Brodie Nolan $^{1,2,5} \mathbb{C}$
}

Received: 12 April 2021 / Accepted: 5 August 2021 / Published online: 16 September 2021

(C) The Author(s), under exclusive licence to Canadian Association of Emergency Physicians (CAEP)/ Association Canadienne de Médecine d'Urgence (ACMU) 2021

\begin{abstract}
Background Severely injured patients benefit from early identification and trauma centre treatment. Ontario has provincial prehospital trauma triage guidelines identifying patients who require direct trauma centre transport. Trauma patients not identified as meeting this provincial trauma triage standard are brought to the closest non-trauma hospital and may later be transferred to a trauma centre by a secondary interfacility transfer. Secondary interfacility transfers cause significant delays in receiving definitive care which have been associated with worse outcomes. The objective of this study was to determine the frequency that patients who underwent emergent secondary interfacility trauma transfer initially met prehospital trauma triage guidelines, as well as to assess the approximate delay to trauma centre care.

Methods Health record review of all injured patients undergoing interfacility transfer to a trauma centre by the provincial critical care transport organization in Ontario, Canada over a 1-year period. The primary outcome of interest was the frequency that patients met the triage standards and which specific criteria were satisfied. Times from patient arrival at the initial non-trauma hospital to initiation of interfacility transfer and from patient arrival at initial non-trauma hospital to arrival at trauma centre were calculated.

Results A total of 460 were included in the study, 372 (80.8\%) of whom met the prehospital triage standard. The largest missed criteria were age greater than 55 years, high-risk motor vehicle collisions, and decreased Glasgow Coma Scale. The median time from initial hospital arrival to trauma centre was $5.7 \mathrm{~h}$ for those patients requiring secondary interfacility transport.

Conclusion Patients who meet trauma triage criteria that end up undergoing secondary interfacility transfer experience significant delays. We recommend adding recreational vehicle collisions as a triage criterion. Emergency physicians should work with their local paramedic services to ensure severely injured patients are identified early to expedite transport.
\end{abstract}

Keywords trauma $\cdot$ prehospital care $\cdot$ triage

\section{Résumé}

Contexte Les patients gravement blessés bénéficient d'un dépistage précoce et d'un traitement au centre de traumatologie. L'Ontario a des lignes directrices provinciales sur le triage préhospitalier des traumatismes qui identifient les patients qui ont besoin d'un transport direct vers un centre de traumatologie. Les patients traumatisés qui ne répondent pas à cette norme

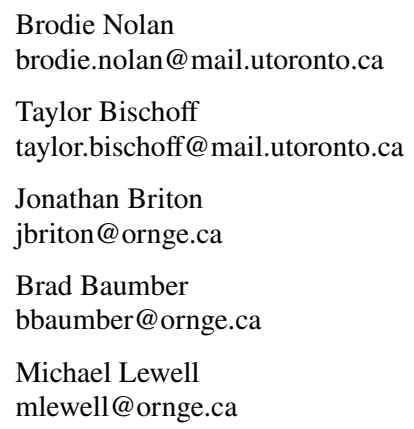

1 Division of Emergency Medicine, Department of Medicine, University of Toronto, Toronto, ON, Canada

2 Ornge, Mississauga, ON, Canada

3 Division of Emergency Medicine, Department of Medicine, Western University, London, ON, Canada

4 Department of Emergency Medicine, London Health Sciences Centre, London, ON, Canada

5 Department of Emergency Medicine, St. Michael's Hospital, Toronto, ON, Canada 
provinciale de triage en traumatologie sont amenés à l'hôpital non traumatologique le plus proche et peuvent plus tard être transférés vers un centre de traumatologie par un transfert inter-établissement secondaire. Les transferts inter-établissements secondaires entraînent des retards importants dans la réception des soins définitifs qui ont été associés à de moins bons résultats. L'objectif de cette étude était de déterminer la fréquence à laquelle les patients qui ont subi un transfert de traumatologie secondaire urgent entre établissements répondaient initialement aux directives de triage préhospitalier des traumatismes, ainsi que d'évaluer le délai approximatif de soins au centre de traumatologie.

Méthodes Examen des dossiers de santé de tous les patients blessés subissant un transfert entre établissements vers un centre de traumatologie par l'organisation provinciale de transport de soins intensifs en Ontario, au Canada, sur une période d'un an. Le critère de jugement principal était la fréquence à laquelle les patients satisfaisaient aux normes de triage et quels critères spécifiques étaient satisfaits. Les délais entre l'arrivée du patient à l'hôpital non traumatologique initial et le début du transfert inter-établissements et entre l'arrivée du patient à l'hôpital non traumatologique intitial et son arrivée au centre de traumatologie ont été calculés.

Résultats Un total de 460 ont été inclus dans l'étude, dont 372 (80,8\%) répondaient à la norme de triage préhospitalier. Les principaux critères manqués étaient l'âge supérieur à 55 ans, les collisions de véhicules automobile à haut risque et la diminution de l'échelle de coma de Glasgow. Le temps médian entre l'arrivée initiale à l'hôpital et le centre de traumatologie était de 5,7 heures pour les patients nécessitant un transport secondaire entre les établissements.

Conclusion Les patients qui répondent aux critères de triage des traumatismes et qui finissent par subir un transfert secondaire entre établissements subissent des retards importants. Nous recommandons d'ajouter les collisions de véhicules récréatifs comme critère de triage. Les médecins d'urgence devraient travailler avec leurs services paramédicaux locaux pour s'assurer que les patients gravement blessés sont identifiés tôt afin d'accélérer le transport.

\section{Clinician's capsule}

What is already known on this subject?

Prehospital trauma triage standards identify patients who require a trauma centre, yet many patients are initially treated at non-trauma centres.

\section{What did the study ask?}

What is the frequency that patients who underwent emergent secondary interfacility trauma transfer initially met trauma triage guidelines?

\section{What did this study find?}

$80.8 \%$ of patients that were a secondary interfacility transfer met triage criteria, resulting in an average delay of $5.7 \mathrm{~h}$.

\section{What does this study matter to clinicians?}

Emergency physicians should work with their local paramedic services to ensure severely injured patients are identified early to expedite transport.

\section{Background}

Trauma patients initially treated at a non-trauma hospital and subsequently transferred to a trauma centre have increased mortality compared to patients brought directly to a trauma centre [1-3]. Therefore, early recognition of patients requiring specialized trauma care in the prehospital environment is critical.

Within Ontario, a provincial prehospital trauma triage guideline identifies patients who should be brought directly to a trauma centre (Supplemental Appendix Fig. 1) [4]. If a patient meets any one criteria of this triage standard, paramedics should transport them directly to a trauma centre, potentially bypassing a closer non-trauma hospital. If a patient is too far or too unstable to facilitate direct transfer but meets the trauma triage criteria, an air ambulance response should be requested to rendezvous at a non-trauma hospital. Interfacility transfers occur when the patient is initially brought to a non-trauma hospital, where they are assessed and then later deemed to require transfer to a trauma centre [5]. Interfacility transfers of injured patients who meet the triage standard should therefore be very low. These cases may occur due to failed application of the standard by paramedics or if an air ambulance response was unable to attend due to weather or competing calls.

Failure of a prehospital system to identify severely injured patients results in delays to care and increased mortality. Evaluation of our prehospital trauma triage is essential. The objective of this study was to determine the frequency that injured patients who underwent a delayed secondary interfacility transfer to a trauma centre in Ontario met the triage standard and identify which specific criteria were satisfied.

\section{Methods}

\section{Study design}

This was a health records review of all injured patients undergoing interfacility transfer to a trauma centre with the 
provincial critical care transport organization in Ontario over 1 year.

\section{Setting}

Ontario has nine adult trauma centres and approximately 150 other acute care hospitals that are non-trauma centres [6]. In Ontario, $40 \%$ of the population lives more than a $60-\mathrm{min}$ drive to a trauma centre and $15 \%$ are more than a $60-\mathrm{min}$ transport by air ambulance [6]. Ornge is the sole provider of air medical transport and critical care transport (land and air) in the province.

\section{Data sources}

Data were derived from a database of electronic patient care records (ePCR) at Ornge. This includes patient demographics, reason for transfer, and vital signs along with a narrative of the patient's history and medical treatment.

\section{Study population}

All emergent interfacility transfers by Ornge that occurred between January 1, 2019 and December 31, 2019 for patients aged 16 years or greater who were transported with injuries to a trauma centre.

\section{Primary outcome}

The primary outcome of interest was the frequency of injured patients who underwent a secondary interfacility transfer met the provincial trauma triage standard and which specific criterion was satisfied. This was determined by manual chart review of the ePCR. Determination of whether a patient met triage criteria was done by one of two paramedic reviewers (JB, BB). To ensure inter-rater reliability a sample of 50 patient charts was assessed by both reviewers, with $100 \%$ agreement (kappa statistic 1.0). Frequency of specific triage criteria were counted. Patients that met more than one triage criteria had counts applied to all criteria satisfied. Reviewers were not blinded to the purpose of the study but were blinded to each other's responses.

\section{Data analysis}

Descriptive statistics were used to evaluate the distribution of data for all variables of interest. Categorical variables were displayed as frequency and percentages. Continuous variables were all found to be non-normally distributed and summarized as medians and interquartile ranges.

Statistical analyses were conducted using SAS Studio version 3.4 (SAS Institute, North Carolina, USA).

\section{Results}

\section{Descriptive statistics}

A total of 10,539 adult emergent transfers were completed between January 1, 2019 and December 31, 2019 with 460 patient meeting inclusion criteria for the study (Supplemental Appendix: Fig. 2). Of these 460 patients, 372 met triage criteria (80.8\%). Patient demographics are shown in Supplemental Appendix Table 1. Recreational vehicle as a mechanism of injury differed significantly between groups, with $19 \%$ of those not meeting the triage standard compared to only $4 \%$ meeting at least one criteria.

The median time from presentation at initial non-trauma hospital to request for interfacility transport was $2.3 \mathrm{~h}$. Time from presentation to initial non-trauma hospital to arrival at trauma centre was $5.7 \mathrm{~h}$ for those that met the triage standard compared to $7.0 \mathrm{~h}$ for those that did not.

\section{Prehospital trauma triage criteria}

Overall, $44.3 \%$ percent of patients met more than one trauma triage criterion. The largest missed criterion was age greater than 55 years. High-risk motor vehicle collisions followed by decreased Glasgow Coma Scale (GCS) and systolic blood pressure less than $90 \mathrm{mmHg}$ were the next most commonly missed criteria (Table 1).

\section{Discussion}

\section{Interpretation of findings}

This study has three important findings. First, over $80 \%$ of patients later transferred to a trauma centre met prehospital trauma triage indications. Second, older age is underutilized as a criterion for transport to a trauma centre. Last, there should be consideration for adding recreational vehicle collisions as a mechanism of injury criterion to the triage standard.

\section{Prior Studies}

Delays to specialized trauma care increases mortality. A recent Ontario study found that injured patients who were transported directly to a trauma centre had lower 24- and 48-h mortality compared to patients who underwent a secondary interfacility transfer [3].

Age has been identified as a factor for undertriage in multiple studies [7]. The American College of Surgeons Committee on Trauma recognized this with their Field Triage Guideline update strengthening their recommendations 
Table 1 Frequency of provincial trauma triage standard criteria met for patients who underwent secondary interfacility transfer
Trauma triage criteria

Total 372 patients met 1 or more criteria $n$, (\%)

\begin{tabular}{ll} 
Physiologic criteria & \\
Patient does not follow commands & $81(21.8)$ \\
Respiratory rate $>30$ or $<10$ per minute & $29(7.8)$ \\
Systolic blood pressure $<90 \mathrm{mmHg}$ & $73(19.6)$ \\
Anatomic criteria & \\
Penetrating head, neck, trunk or proximal limb injury & $39(10.5)$ \\
Chest wall instability or deformity & $38(10.2)$ \\
Two or more proximal long bone fractures & $8(2.2)$ \\
Crushed, degloved, mangled or pulseless extremity & $2(0.5)$ \\
Amputation (proximal to wrist or ankle) & $0(0.0)$ \\
Pelvic fracture & $35(9.4)$ \\
Open/depressed skull fracture & $16(5.0)$ \\
Paralysis & $8(2.2)$ \\
Mechanism of injury criteria & \\
Fall $>6$ m & $37(9,9)$ \\
High risk motor vehicle collision criteria & $89(23.9)$ \\
Pedestrian or cyclist struck & $22(5.9)$ \\
Motorcycle crash & $38(10.2)$ \\
Special criteria & \\
Age $>55$ years & $184(49.5)$ \\
Anticoagulant or bleeding disorder & $7(1.9)$ \\
Burns with traumatic mechanism & $4(1.1)$ \\
Pregnancy $>20$ weeks & $0(0.0)$ \\
\hline
\end{tabular}

trauma transfer for older adults [8]. This study found age greater than 55 was the largest missed trauma triage criterion in patients who underwent secondary interfacility transfer. Of patients that met only the age criteria, 54\% were found to have a fall down stairs. While the current triage standard does not include this as a mechanism of injury criteria, our findings suggest that a large number of older patients would benefit from this inclusion.

The kinetics of trauma are similar for motorcycle and recreational vehicle injuries, with unrestrained drivers and passengers in open air compartments and a high likelihood of roll-over, pinning, and rider ejection [9]. A Canadian study found that the mortality rate of all-terrain vehicle (ATV) trauma was $17 \%$, with $30 \%$ of patients requiring post discharge care [10]. We found a significant trend of recreational vehicle collisions (i.e. ATV, snowmobile or watercraft) occurring more frequently in patients that did not meet trauma triage criteria. With strict application of the triage standards, recreational vehicle trauma patients did not meet the criteria yet had a high need of interfacility transfer for trauma care. Recreational vehicles and motorcycle accidents should be considered similarly given their comparable trauma kinetics and association with significant morbidity and mortality $[9,10]$.

\section{Strengths and limitations}

This study has several limitations. For one, the study authors did not have access to the initial paramedic call report from the first on-scene paramedics. There are over 70 different paramedic services across Ontario, which would have required data sharing agreements in place with each of these. Therefore, physiologic parameters used were recorded at the time of transport paramedic arrival at sending facility, not at the time of initial paramedic contact. This means some instances of physiologic inclusion might be incorrect as vital signs are often dynamic with severely injured patients. Last, given the database was limited to a provincial transport service, in-hospital outcomes were not available and any impact on mortality is unable to be explored.

\section{Clinical implications}

Prehospital trauma triage guidelines exist to identify injured patients who benefit from rapid transport to a trauma centre [1-4]; however, more than three quarters of our patients were not identified as meeting triage criteria resulting in delays to definitive care. This may be due to inadequate understanding of the guidelines or paramedic bias. Inadequate 
understanding could include insufficient training, the standards being too complex or not amenable to rapid field application. Paramedic bias might be related to the availability of transport assets, a history of prior unsuccessful requests for an air ambulance, or impression of patient injury or mechanism (survivability of injury or patient factors such as age and comorbidity). Last, transports might have initially been identified as meeting trauma triage; however, dispatch services, scene paramedics or sending physicians might have cancelled the scene or modified scene transport, only to later discover the extent of injuries.

Emergency physicians should work with their local paramedic services to ensure prehospital trauma triage guidelines are being followed. Routine audits may also identify modifications to improve these guidelines.

\section{Research implications}

Future research should explore the challenges faced in paramedic identification of patients meeting trauma triage and an examination of barriers and perception to trauma triage.

\section{Conclusion}

Prehospital trauma triage guidelines exist to identify patients that would most benefit from direct transfer to a trauma centre. We found significant delays in transfer of trauma patients who clearly met trauma triage criteria. We recommend adding recreational vehicle collisions to the triage standard. Emergency physicians should work with their local paramedic services to ensure severely injured patients are identified early to expedite transport.

Supplementary Information The online version contains supplementary material available at https://doi.org/10.1007/s43678-021-00192-x.

Author contribution $\mathrm{BN}, \mathrm{JB}, \mathrm{BB}$ and ML conceived and designed the study and obtained research ethics approval. BN, TB, JB and TB performed data collection. $\mathrm{BN}$ and $\mathrm{TB}$ analyzed the data. TB drafted the manuscript, and all authors contributed substantially to its revision. BN takes responsibility for the paper as a whole.

Funding There was no funding provided for this study.

\section{Declarations}

Conflict of interest There are no conflicts of interest to declare.
Data availability Deidentified participant data may be available upon reasonable request by contacting the study authors.

Research ethics approval The research ethics board at the University of Toronto approved this study (REB number 39619).

\section{References}

1. Garwe T, Cowan LD, Neas B, et al. Survival benefit of transfer to tertiary trauma centers for major trauma patients initially presenting to Nontertiary Trauma Centers. Acad Emerg Med. 2010;17(11):1223-32.

2. Mackenzie EJ, Rivara FP, Jurkovich GJ, et al. A national evaluation of the effect of trauma-center care on mortality. N Engl J Med. 2006;354(4):366-78.

3. Haas B, et al. The mortality benefit of direct trauma center transport in a regional trauma system: a population-based analysis. $\mathrm{J}$ Trauma Acute Care Surg. 2012;72:1510-5 (discussion 1515-7).

4. Canada, Ontario Ministry of Health. Emergency Health Regulatory and Accountability Branch Ministry of Health. Basic Life Support Patient Care Standards, vol. 3.3. Queen's Printer for Ontario; 2021. pp. 24-29.

5. Nolan B, Tien H, Sawadsky B, et al. Comparison of helicopter emergency medical services transport types and delays on patient outcomes at two Level I Trauma Centers. Prehosp Emerg Care. 2017;21(3):327-33.

6. Gomez D, Haas B, Doumouras AG, et al. A population-based analysis of the discrepancy between potential and realized access to trauma center care. Ann Surg. 2013;257(1):160-5.

7. Amoako J, Evans S, Brown NV, et al. Identifying predictors of undertriage in injured older adults after implementation of statewide geriatric trauma triage criteria. Acad Emerg Med. 2019;26(6):648-56.

8. Sasser SM, Hunt RC, Faul M, et al. Guidelines for field triage of injured patients recommendations of the national expert panel on field triage, 2011. Centers Dis Control Prev Morb Mortal Wkly Rep. 2012;61(1):1-21.

9. Fawcett V, Tsang B, Taheri A, et al. A review on all terrain vehicle safety. Safety. 2016;2:15.

10. Krauss EM, Dyer DM, Laupland KB, et al. Ten years of all-terrain vehicle injury, mortality, and healthcare costs. J Trauma Injury Infect Crit Care. 2010;69(6):1338-43. 